\title{
Gender Representation in EFL Textbooks in Saudi Arabia: A Critical Discourse Analysis Approach
}

\author{
Wafa Aljuaythin*
}

Department of English Language and Literature, College of Arts, King Saud University, Saudi Arabia

Corresponding Author: Wafa Aljuaythin, E-mail: waljuaythin@ksu.edu.sa

\author{
ARTICLE INFO \\ Article history \\ Received: March 18, 2018 \\ Accepted: May 07, 2018 \\ Published: September 01, 2018 \\ Volume: 7 Issue: 5 \\ Advance access: July 2018

\section{Conflicts of interest: None} \\ Funding: This research \\ project was supported by \\ a grant from the Research \\ Center for the \\ Humanities, Deanship of \\ Scientific Research, King \\ Saud University
}

\begin{abstract}
This study investigates the representation of gender in two English as a Foreign Language textbooks for elementary students in Saudi schools. It employs the three stages of Fairclough's (2015) three-dimensional model: description, interpretation, and explanation. The analysis phase of the description stage is concerned with analyzing four aspects: the frequency of male and female occurrences, the kinds of activity that the two genders engage in, the pictorial representations of the two genders, and the social and domestic roles associated with males and females. Subsequently, after compiling quantitative data on these aspects, the analysis moves to a qualitative interpretation of these aspects in relation to the social context. In the final stage of the analysis, when the discussion aims to reach a final critical explanation on the macro level, the underlying ideological functions of power relations and social struggles are explained in terms of the dominance approach to language (Spender, 1980). The analysis of the two textbooks reveals a gender imbalance in favor of males. This imbalance has led to the representation of women as marginalized and stereotypical figures. This study suggests that such an underrepresentation of women could create a false reality surrounding perceptions of women and hinder the process of ensuring equality to all humans. Nevertheless, in line with Spender's view of language as not only an inhibiting vehicle but also a creative one, this paper indicates that a symmetrical representation of gender in textbooks could enhance female empowerment in Saudi Arabia.
\end{abstract}

Key words: EFL Textbooks, Stereotyping, Gender, Female Roles, Critical Discourse Analysis, Material Evaluation

\section{INTRODUCTION}

The importance of textbooks in teaching and learning cannot be denied (Richards, 2009). They provide a consistent and convenient way to learn for a good number of teachers and learners. In English as a Foreign Language (EFL) context, teachers consider textbooks as the basic foundation for their teaching, and learners are introduced to the foreign language through these textbooks (Ahmad \& Shah, 2014). Sulaimani (2017) argues that in a country like the Kingdom of Saudi Arabia, EFL textbooks hold an authoritative status in that they contribute to potentially influencing learners' ideologies regarding different issues. Saudi students may be influenced by the religious, social, educational, and cultural aspects of the foreign language context while learning the foreign language. However, even given the significance afforded to EFL textbooks in Saudi Arabia, it seems that they have not received sufficient evaluation, specifically in terms of gender-biased representation. Therefore, this paper aims to uncover gender stereotyping and patriarchal ideologies in several EFL textbooks intended for the Saudi context but compiled overseas. By employing Fairclough's (2015) three-dimensional model of critical discourse analysis, this paper aims to understand the perceptions of gender roles and stereotyping in Saudi elementary-level EFL textbooks. The significance of this study stems from the need to deconstruct and challenge gender asymmetry as part of a quest for change and improvement, especially because gender asymmetry can perpetuate ideologies that can keep women in a subordinate position. In fact, to the best of the researcher's knowledge, a very limited number of studies have adopted this quest in the context of Saudi EFL textbooks, and as such, the current study aims to enrich the fields of gender studies and material evaluation. It addresses the following two research questions:

1. Do Saudi EFL textbooks for elementary schools contain patriarchal ideologies and gender stereotyping?

2. To what extent do they represent gender asymmetry?

\section{LITERATURE REVIEW}

\section{The History of EFL Textbooks in Saudi Arabia}

EFL textbooks in Saudi Arabia have gone through many phases of improvement that have continued to the present 
day. In the 1960s-80s, Living English for the Arab World was the main EFL textbook used in the country (Al-Seghayer, 2005). It was directed at all Arab learners of English in the Arab world. Subsequently, the series Saudi Arabian School English was developed by the Saudi Ministry of Education to address local needs and cultures (AlJumiah, 2016). During the 1990s, a newer series called English Language for Saudi Arabia was introduced into the Saudi educational system (Mahboob \& Elyas, 2014). However, after 9/11, a shift in Saudi education took place, especially with regard to EFL education. For example, English was introduced in elementary schools as a compulsory subject. Furthermore, while earlier series of English textbooks focused on representing the local culture with no reference to the target language's culture, the revised versions of EFL textbooks advocated the introduction of the foreign language's culture and thinking from a cross-sociocultural perspective (Elyas, 2008). These newer English textbooks are developed in the UK or US but are only directed at Saudi learners as they are customized to meet the needs of Saudi Arabian culture while preserving the values of the target language's culture (AlJumiah, 2016). However, with the significant evaluations and changes that Saudi EFL textbooks have gone through, there is still an ongoing controversy over how they deal with culturally and socially specific issues, such as gender representation.

\section{Language, Gender, and Stereotyping}

Gender can be considered as one of the under-researched topics in the field of material evaluation. According to Dai (2015), gender refers to social and cultural values, practices, and roles that differentiate males from females; hence, gender roles are not natural but are acquired to meet society's expectations of gender identities. Chandler (1997) further claims that gender roles are socially constructed as gender behaviors are learned rather than innate. For instance, men are usually identified as strong, intellectual, and independent, while women are supposed to be sensitive, caring, and child-friendly (Hussain, Naz, Khan, Daraz, \& Khan, 2015). Accordingly, gender proves to be performative within the borders of a given culture and society (Butler, 1990), i.e. each society expects the performance of gendered behaviors based on the biological sex of those carrying out the performance. Hussein et al. (2015) argue that those social and cultural conceptualizations of gender lead to the development of gender stereotyping. In the same respect, Suter (2006) maintains that gender stereotypes are deep-rooted understandings of the characteristics of males and females, which support the continuity of specific gender roles. Language, as an example, can contribute to the construction of gender stereotyping and sexism. This approach to language, known as the dominance approach, was proposed by Spender (1980) in her book Man Made Language. This approach argues that differences in the use of language that led to an imbalanced perception of gender were the result of men's domination of women. This view mainly focuses on power distribution in society, in which women are subordinate to men, and this subordination is manifested in the language and perceptions of men and women and their expected roles. Eckert and McConnell-Ginet (2013) further argue that the continuous subordination of women not only reflects their position in society but also keeps them in that position. Another factor that can also contribute to the formation and continuation of gender roles and stereotyping manifests in textbooks. Mustapha (2013) argues that imbalanced or biased presentations of males and females directly shape gender identities and ideologies, which might clash with the educational goal of the contemporary society, especially the need for gender equality and female empowerment. As such, different analytical and theoretical frameworks are being utilized to evaluate the gender power imbalance in textbooks, such as critical discourse analysis (CDA).

\section{Fairclough's Three-Dimensional Model of Critical Discourse Analysis}

CDA is an influential framework that can be used to evaluate gender ideologies in textbooks (Fairclough, 2015). It involves the investigation of ideological manipulation, hegemony, and power relations (Rahimi \& Sahragard, 2007). Clark (1995) argues that critical analysis aims to explore issues related to gender, ideology, and identity, as well as how these issues are reflected in a text. In other words, CDA can be used to investigate the relationship between the use of language and the political and social contexts in which it occurs (Paltridge, 2006). It also illuminates the role of language in constructing and reconstructing social relations; hence, Fairclough (2015) claims that CDA deconstructs texts to explore power relations in the social and political worlds. In fact, Fairclough is one of the influential figures in this discipline. He is widely known for his three-dimensional model of discourse. He maintains that discourse is simultaneously a language text (whether spoken or written), discursive practice (which is the production, distribution, and comprehension of a text), and social practice (which is the text's place in the societal level).

Fairclough (2015) correspondingly developed three stages of discourse analysis: description, interpretation, and explanation. Description refers to the analysis of a text. It is the description of the linguistic devices used in a text. Interpretation is more concerned with the analysis of discourse practices to examine the relationship between the productive and interpretative discursive processes and the text, with reference to the situational context of the text. Explanation is associated with the analysis of a social practice. Whereas interpretation is concerned with the relationship between the discursive practice and the text, explanation looks at the relationship between the discursive and social processes. In other words, it aims to analyze the discourse within a wider social scope in order to identify societal determination and the social effects of discourse (Dai, 2015). In this respect, the explanation aims to locate and explain the text within a wider social and cultural scope in order to show how it is determined by social structures. Given the orientation of Fairclough's approach to CDA, "social structures" mainly refers to power relations and social struggles. 


\section{Practical Studies on Gender Stereotyping in EFL Textbooks}

The evaluation of EFL textbooks in terms of gender misrepresentation is a never-ending process, as textbooks are numerous and ideologies are diverse. Many scholars have attempted to evaluate textbooks with a focus on gender representation (AlJumiah, 2016; Amerian \& Esmaili, 2015; Jannati, 2015; Samadikhah \& Shahrokhi, 2015; Sulaimani, 2017). For instance, Jannati (2015) compared gender roles as they appeared in Iranian EFL textbooks by focusing on adjectival and pictorial representations; thus, both content and semiotic analyses were employed in the study. The findings indicated a gender bias and stereotyping in favor of males. In terms of the picture analysis, the findings also indicated that stereotypical gender roles, such as the role of nurturer and the performance of domestic activities, were significantly associated with women. Another study with the same aim was conducted by Samadikhah and Shahrokhi (2015), also in Iran, but this time from a CDA perspective. Fairclough's (2015) three-dimensional model of CDA was adopted in the study for the fair description, interpretation, and explanation of gender representations in these textbooks. The study analyzed the textbooks in terms of nine major aspects of gender, such as female and male characters, female and male pictorial representations, female and male titles, activities, and the status of females and males in mixed-gender dialogues. The findings showed that the representation of gender in the textbooks contained instances of gender bias in favor of men, suggesting that traces of a power imbalance exist in textbooks. Amerian and Esmaili (2015) conducted a similar study that evaluated gender in EFL textbooks, which used Fairclough's (2015) three-dimensional model of CDA. The findings of their study indicated that the textbooks contained instances of sexism, both overt and covert. The overt sexism was presented as discrimination against women and the covert consisted of drawing women as instruments for advertising. The study also indicated that the discourse of marketing and advertising, which usually exploits women, was adopted by these textbooks.

In the case of Saudi Arabia, two studies have been carried out with the aforementioned aim. The first was conducted by AlJumiah (2016), who investigated social power relations in terms of gender and race in high-school-level international EFL textbooks made for the Saudi context. The method for analyzing these textbooks was Fairclough's $(1989,2015)$ dialectical-relational approach to CDA. The findings revealed that hidden discourses in the EFL textbooks reproduced and maintained gender ideologies, such as male dominance and women's marginalization. The other study conducted in the Saudi context was carried out by Sulaimani (2017). She also examined international EFL textbooks made for the Saudi context from a CDA perspective, but this time with university students. The findings suggested that the textbooks were gender biased in favor of men, as women were dismissed in almost half of the units of the textbooks.

As can be inferred from the aforementioned discussion, gender in Saudi EFL textbooks is an under-researched topic. As such, the present study aims to enrich the fields of ma- terial evaluation and gender studies by providing a critical gender evaluation of elementary-level English textbooks (namely Smart Class) in Saudi Arabia. This study is consistent with other Saudi studies because it examines EFL textbooks made for the Saudi context; however, it differs in terms of the specific tools used to accomplish this aim. The tools utilized for the analysis were adapted from the aforementioned Iranian studies, which employed Fairclough's (2015) three-dimensional model of CDA.

\section{METHODOLOGY}

\section{Materials}

The textbooks examined were two EFL textbooks from the series Smart Class, aimed at Saudi elementary students. They are produced by MM Publications in the UK and authored by H. Q. Mitchell and Marileni Malkogianni. The textbooks examined in the study were Smart Class 5 and Smart Class 6, intended for use in the first semester and second semester of sixth grade, respectively. Each textbook contains four modules that cover topics such as family, friends, and hometowns. The reason behind selecting these two textbooks was that they could provide rich data for the analysis, especially since the other Smart Class textbooks are aimed at beginner learners of English (i.e., fourth- and fifth-grade students) and hence deal with simpler topics.

\section{Instrument}

As mentioned earlier, Fairclough's (2015) three-dimensional model of CDA was used as the framework for the analysis. The first stage of this model is describing the linguistic items in the text. The second stage is providing an interpretation of the use of these linguistic items and devices. The final stage, explanation, aims to analyze the claims provided earlier within the social and cultural contexts. Therefore, description is concerned with the text only, interpretation is concerned with the social context, and, more broadly, explanation is associated with a wider social scope.

\section{Procedure}

The procedure in this study was adapted from Amerian and Esmaili (2015), with minor changes. In their study, they utilized Fairclough's (2015) checklist for examining gender power in textbooks. However, this study focuses on only four items from that checklist. The other five items on the checklist that deal with semantic and syntactic gender analysis were not investigated in this study as they deal with deeper issues that cannot be traced using Smart Class, since it is intended for Saudi beginner-level English learners. The analysis of the description stage was started by analyzing the four aspects: frequency of male and female occurrences, kinds of activity that the two genders engaged in, pictorial representations of the two genders, and social and domestic roles associated with males and females. To ensure the reliability of the compiled data, the numbers and frequencies were checked and revised twice by the researcher. Subse- 
quently, after compiling quantitative data for these aspects, the analysis moved to a qualitative interpretation of these aspects in relation to the social context. In the final stage of the analysis, where the discussion aimed to reach a final critical explanation on the macro level, the underlying ideological functions of power relations and social struggles were explained in terms of the dominance theory (Spender, 1980) and as an outcome of incorrect stereotyping.

\section{RESULTS AND DISCUSSION}

\section{Description}

This section starts with Fairclough's (2015) first stage of CDA, which is description. This stage begins by reporting and describing the data from the two textbooks regarding the four aspects mentioned earlier.

\section{Female and male occurrences}

The first aspect analyzed in the two textbooks was the frequency of female and male occurrences. As shown in Figure 1, females were underrepresented in the two textbooks. Only 178 incidences of female occurrence appeared in the textbooks, while almost 445 cases were reported for male occurrences. These numbers indicate that males were the focus of more than two in every three representations of gender.

\section{Activity frequency of females and males}

The second aspect examined was the kinds of activity that females and males engaged in. As seen in Table 1, males were depicted performing activities more frequently than females. Approximately two thirds of the activities were performed by males, with the remaining one third being left for females, contributing about 275 and 107 cases, respectively. The analysis of this aspect also suggested that the activities were gender specific. In other words, there were specific activities performed more frequently by males, such as "eating in restaurants" and "going on vacations," whereas "shopping" and "housework" were more associated with females. There was a huge gender imbalance in some activities, such

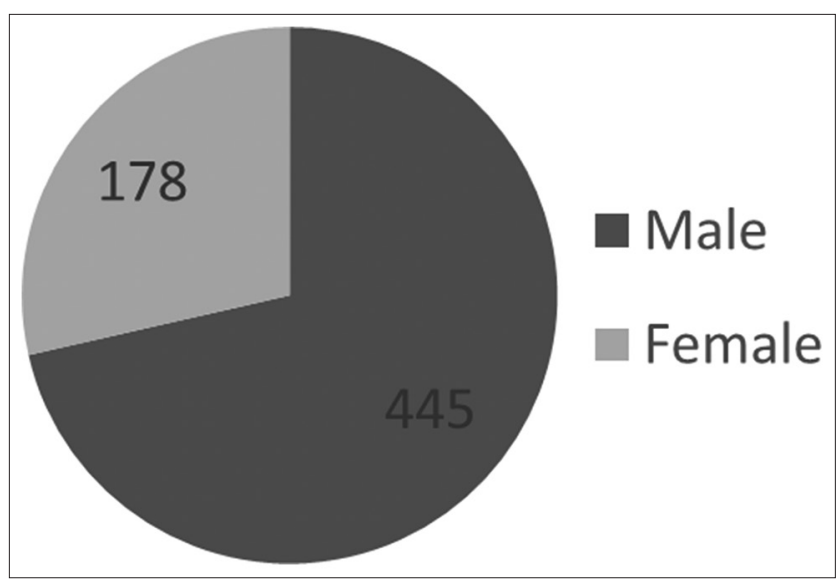

Figure 1. Frequencies of female and male occurrences as "driving," "work," and "engaging in sports," in favor of males. For example, 23 cases were reported of males as drivers of cars, buses, or even bicycles, whereas none were reported for females. In addition, 33 incidences showed males at work, while only 8 were reported for females. In terms of "engaging in sports," 82 cases were reported of males engaging in different types of sport, such as football, basketball, volleyball, and swimming, while only 4 cases were reported for females, and all of them revolved around swimming.

\section{Pictorial representation of females and males}

The third aspect was concerned with pictorial representations of females and males. As shown in Figure 2, there was a huge and significant preference for representing males only in the pictures in the textbooks. Approximately three quarters of all pictures in the textbooks depicted males only, avoiding the representation of females. To illustrate, 244 pictures represented males only, while 40 portrayed females only. Additionally, when pictures included both sexes, the depiction of male figures outnumbered that of female figures. Furthermore, only 10 pictures had equal numbers of females and males.

\section{Social and Domestic Roles}

The fourth aspect examined was the social and domestic roles with which the two genders were associated. As shown in Table 2, the roles, like the activities, were gender specific. In these textbooks, some roles were stereotypically associated more frequently with females than males, such as "nurse." On the other hand, other roles were stereotypically associated with males, such as "lifeguard" and "firefighter." In terms of the roles performed by both sexes, there appeared a significant gender imbalance. For instance, there were six

Table 1. Activity frequency of females and males

\begin{tabular}{lcc}
\hline Kind of activity & $\begin{array}{c}\text { Female } \\
\text { frequency }\end{array}$ & $\begin{array}{c}\text { Male } \\
\text { frequency }\end{array}$ \\
\hline Driving & 0 & 23 \\
Shopping & 4 & 1 \\
Going on vacation & 0 & 3 \\
Eating in restaurants & 0 & 3 \\
Work & 8 & 33 \\
Studying/at school & 10 & 19 \\
Playing & 1 & 6 \\
Watching TV & 1 & 0 \\
Engaging in social activities & 10 & 46 \\
Engaging in sports & 4 & 82 \\
Engaging in personal activities & 6 & 34 \\
Travelling & 1 & 4 \\
Housework & 39 & 0 \\
Outdoor activities & 19 & 14 \\
Painting & 4 & 9 \\
Total & 107 & 275 \\
\hline
\end{tabular}




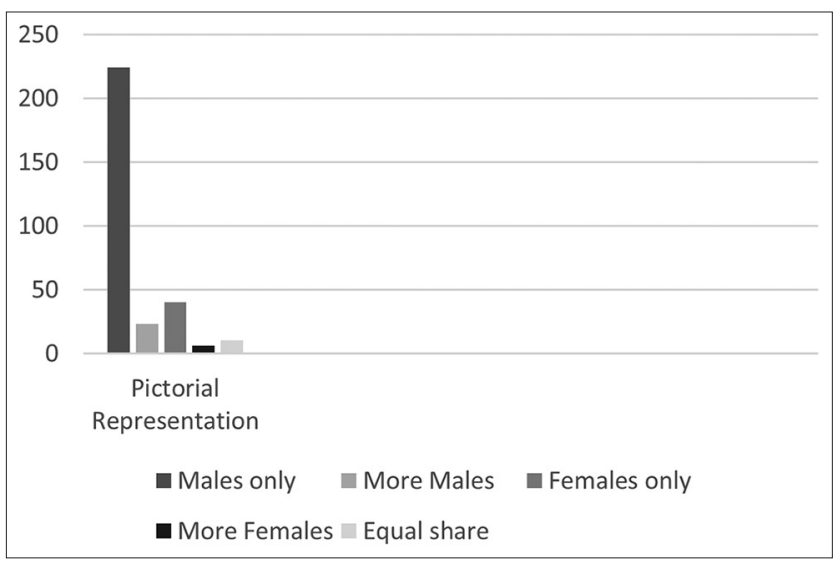

Figure 2. Pictorial representation of females and males

Table 2. Social and domestic roles of females and males

\begin{tabular}{lcc}
\hline Social/domestic role & $\begin{array}{c}\text { Female } \\
\text { frequency }\end{array}$ & $\begin{array}{c}\text { Male } \\
\text { frequency }\end{array}$ \\
\hline Parent & 22 & 10 \\
Teacher & 3 & 9 \\
Student & 7 & 9 \\
Doctor & 1 & 6 \\
Son/daughter & 14 & 11 \\
Friend & 14 & 51 \\
Nurse & 4 & 0 \\
Lifeguard & 0 & 7 \\
Firefighter & 0 & 5 \\
\hline
\end{tabular}

cases of males as doctors, but only one of a female doctor, and in this single case, she was a dentist. Additionally, there were 51 cases of males being depicted as "friends," but only 14 for females. Males as "teachers" and "students" also outnumbered females in those roles. Females as "mothers" or "daughters" outnumbered males as "fathers" or "sons."

\section{Interpretation and Explanation}

Next come the second and third stages of Fairclough's (2015) model, where the analysis interprets the data in relation to the social context and, more broadly, to the social process. Accordingly, the findings are related to three crucial themes: gender asymmetry and stereotyping in the textbooks, patriarchal ideology, and adopting a local perspective.

\section{Gender asymmetry and stereotyping in the textbooks}

Based on the results discussed earlier, one can argue that females were underrepresented in both textbooks of Smart Class. This underrepresentation does, in fact, make the books seem male oriented. In terms of pictorial representations, it can be argued that females are nearly invisible and marginalized in both textbooks. Even when females were represented, there was a tendency to rely on stereotypical perceptions of them, such as that of a "nurturer," which was seen in the portrayal of females as mothers, nurses, or housewives. This stereotypical depiction of females could in fact create a false perception of females in the Saudi society. Unlike females, males in these textbooks were depicted doing a wide range of activities and occupying many roles, which also supported the gender imbalance.

Moving to a wider perspective, this study's findings are consistent with those of the studies cited in the literature review section (AlJumiah, 2016; Amerian \& Esmaili, 2015; Jannati, 2015; Samadikhah \& Shahrokhi, 2015; Sulaimani, 2017). The current study suggests, as with previous studies, that EFL textbooks contain instances of gender imbalance and stereotyping in favor of males. As with previous studies, the presence of men in these textbooks significantly outweighs that of women. Besides, when women are portrayed, there is a strong tendency to depict them in a stereotypical manner.

\section{Patriarchal ideology}

Additionally, the gender power imbalance in these textbooks can be seen as systems of power that interact to construct and reconstruct patriarchal power, and in this respect, constrain the attainment of equality for all human beings. This claim can be supported with the aid of the dominance approach to language (Spender, 1980). In her book Man Made Language, Spender argues that language limits the world because it constructs reality by giving those in power, in this case men, the ability to manipulate it. In terms of this study, the encoding of asymmetrical gendered language in the textbooks could influence societal gender perspectives, and thus the realization of reality. In other words, asymmetrical gender representation in EFL textbooks could cause inaccurate perceptions of cultural and social reality. In addition, the continuous representation of these stereotypical female roles teaches students that these roles are the only acceptable ones for women, reducing the possibility of females practicing roles that are typically associated with males. In a similar vein, Sulaimani (2017) speculates that maintaining such portrayals of men and women in textbooks can, in fact, shape a reality in a society; hence, reinforcing gender biases through learning materials could contribute to slowing down the process of establishing equality among people. Nevertheless, Spender (1980) furthers argues that language can not only be considered an "inhibiting vehicle" but also a "creative" one. In this sense, Spender posits that language provides potential freedom because it allows people to construct the world they want to live in. In Saudi Arabia, the status of women is improving rapidly, and Islam promotes equality for all human beings. Thus, the process of female empowerment is, in fact, hindered by the asymmetrical representation of gender in textbooks; a symmetrical representation could enhance female empowerment in Saudi Arabia.

Moreover, the fact that the two textbooks under examination are aimed at elementary school students raises a serious concern regarding the ideology that these children will eventually grasp and internalize. Gharbavi and Mousavi (2012) argue that gender imbalanced textbooks can cause disturbing feelings for female students, including feelings of marginalization, exclusion, devaluation, and lowered expec- 
tations. Besides, Sulaimani (2017) argues that biased gender representation in textbooks promotes the ideology of female marginalism among female students.

\section{Adopting a Local Perspective}

Additionally, it can be argued that since these textbooks were not written by Saudis, they rely on stereotypical false ideologies of Saudi society. It is believed in the West that women in Saudi Arabia are oppressed and marginalized (Rajkhan, 2014), but in fact, that is not the case anymore. The enrollment of Saudi women in universities has exceeded that of males since 2010 (Smith \& Abouammoh, 2013). According to statistics from the Saudi Ministry of Education from 2015-2016, 150,311 female students enrolled in universities in undergraduate programs in Saudi Arabia, which is 51\% of the overall number of undergraduate students (Education Statistic Center, 2016). This indicates that Saudi society has succeeded in empowering women through education. Additionally, Saudi women have finally been allowed to drive, and this can also be considered another act of female empowerment. Hence, EFL textbooks that are produced in Saudi Arabia by Saudis could be of great significance, as they would understand the specific and current state of the local culture.

\section{CONCLUSION}

This study investigated the representation of gender in two Saudi EFL textbooks for elementary students. It aimed to understand gender roles and stereotyping in these textbooks in order to enrich the field of material evaluation and gender representation, as only few studies have focused on this issue. The goal of this paper was to deconstruct gender asymmetry in a quest of change and improvement. The significance of this study was that best to the researcher's knowledge, no other study aimed to critically analyze Saudi EFL textbooks that are aimed for elementary students. It employed CDA, specifically Fairclough's (2015) three-dimensional model of analysis. The analysis of these two textbooks revealed a gender imbalance in favor of males. This imbalance has led to the representation of women as marginalized and stereotypical. This study also suggested that such an underrepresentation of women could create a false reality about women and hinder the process of gaining equality for all humans.

There were several limitations in this study that are worth mentioning. For instance, examining a larger sample would contribute to generalizing the findings to all Saudi EFL textbooks. In addition, examining other Saudi EFL textbooks, such as Full Blast and Traveller, which are aimed at older students, may result in new and interesting findings, as the topics are different.

This research could be followed up by an interesting contrastive analysis between the EFL textbooks created for the Saudi context and the international versions of the same textbooks. In addition, exploring the perceptions of the students to see if the textbooks have in fact succeeded in internalizing a patriarchal ideology in their minds would be of great importance in an examination of the impact of textbooks' ideologies on students.

\section{ACKNOWLEDGMENT}

The author would like to thank the Deanship of Scientific Research and RSSU at King Saud University for their technical support.

\section{REFERENCES}

Ahmad, H. \& Shah, S. (2014). EFL textbooks: Exploring the suitability of textbooks' contents from EFL teachers' perspectives. Transactions on Education and Social Sciences, 5(1), 12-20.

AlJumiah, A. (2016). Language, power, and ideology in high school EFL textbooks in Saudi Arabia. (Doctoral of Philosophy), University of New Mexico, Albuquerque, New Mexico.

Al-Seghayer, K. (2005). Teaching English in the Kingdom of Saudi Arabia. In G. Braine (Ed.), Teaching English to the world: History, curriculum, and practice.123-142. Mahwah, NJ: Lawrence Erlbaum Associates.

Amerian, M. \& Esmaili, F. (2015). Language and gender: A critical discourse analysis on gender representation in a series of international ELT textbooks. International Journal of Research Studies in Education, 4(2), 3-12 doi:10.5861/ijrse.2014.963

Butler, J. (1990). Gender trouble: Feminism and the subversion of identity. New York \& London: Routledge.

Chandler, D. (1997). Children's understanding of what is 'real' on television: A review of the literature. Journal of Educational Media, 23(1), 65-80. doi: https://doi. org/10.1080/1358165970230105

Clark, R. (1995). Developing critical reading practices. Prospect: The Journal of Australian TESOL, 10, 65-81.

Dai, G. (2015). Constituting gender roles through the transitivity choice in commodity advertising. Asian Social Science, 11(28), 58-64. doi:10.5539/ass.v11n28p58

Eckert, P., \& McConnell-Ginet, S. (2013). Language and gender. Cambridge: Cambridge University Press.

Elyas, T. (2008). The attitude of American English within the Saudi educational system. Novitas-Royal. Research on Youth Language, 2(1), 28-48.

Education Statistic Center. (2016). Higher education statistics of newly enrolled undergraduate students (20152016). (Online), Retrieved May 2, 2018. Ministry of Education. www.moe.gov.sa/en/HigherEducation/governmenthighereducation/Pages/AdmissionStatistics. aspx.

Fairclough, N. (1989). Language and power. London: Longman.

Fairclough, N. (2015). Language and power. London: Routledge.

Gharbavi, A., \& Mousavi, S. A. (2012). A content analysis of textbooks: Investigating gender bias as a social prominence in Iranian high school English textbooks. English Linguistics Research, 1(1), 24-49. https://doi. org/10.5430/elr.v1n1p42

Hussain, M., Naz, A., Khan, W., Daraz, U., \& Khan, Q. (2015). Gender stereotyping in family: An institutionalized and normative mechanism in $\mathrm{Pa}$ - 
khtun society of Pakistan. SAGE Open, 5(3), 1-11. doi: $10.1177 / 2158244015595258$

Jannati, S. (2015). Gender representation in EFL textbooks: A case of ILI Pre-intermediate series. Journal of Applied Linguistics and Language Research, 2(3), 211-222.

Mahboob, A. \& Elyas, T. (2014). English in the Kingdom of Saudi Arabia. World Englishes, 33(1), 128-142.

Mustapha, A. S. (2013). Gender and language education research: A review. Journal of Language Teaching and Research, 4(3), 454-463. doi:10.4304/j1tr.4.3.

Paltridge, B. (2006). Discourse analysis: An introduction. London: Bloomsbury.

Rajkhan, S. (2014). Women in Saudi Arabia: Status, rights, and limitations. University of Washington Bothell, King County.

Rahimi, A. \& Sahragard, R. (2007). Critical discourse analysis. Tehran: Jungle Publications.
Richards, J. C. (2009). Curriculum development in language teaching. Cambridge, U.K.: Cambridge University Press.

Samadikhah, M. \& Shahrokhi, M. (2015). A critical discourse analysis of ELT materials in gender representation: A comparison of Summit and Top Notch. English Language Teaching, 8(1), 121-133. doi:10.5539/elt.v8n1p121

Smith, L. \& Abouammoh, A. (2013). Higher education in Saudi Arabia: Achievements, challenges and opportunities. New York: Springer. https://doi.org/10.1007/97894-007-6321-0

Spender, D. (1980). Man made language. London: Rutledge and Keegan Paul.

Sulaimani, A. (2017). Gender Representation in EFL Textbooks in Saudi Arabia: A Fair Deal? English Language Teaching, 10(6), 44-52. doi:10.5539/elt.v10n6p44

Suter, C. (2006). Trends in gender segregation by field of work in higher education. Paris: OECD. 